\title{
Acute Pain Services during Covid-19: Challenges and Solutions
}

\author{
Samarjit Dey ${ }^{1^{*}}$, Sunny Malik ${ }^{2}$ \\ ${ }^{1}$ Associate Professor, Department of Anaesthesiology, Critical care, Pain \& Palliative Care, AIIMS \\ Raipur, Chhattishgarh-492099, India, ${ }^{2}$ Consultant, Pain and Palliative Care, RGCIRC, Nitibagh, \\ New Delhi-110049, India
}

Editor, since the WHO has declared Covid-19 as a pandemic ${ }^{1}$, the healthcare fraternity worldwide has been diverted towards tackling and managing patients infected with Covid-19. Though nonessential surgeries are being postponed all over the world ${ }^{2}$, malignancies, obstetric cases and semi emergency surgeries are being operated and certainly management of postoperative pain in these group of patients is a matter of concern. Acute pain service team usually manages postoperative pain in all surgical cases. During this Covid-19 pandemic, management of postoperative pain has definitely been affected by the restrictions of movement of acute pain team members within the hospital and this has led to less interaction with the patients.

\section{Challenges to continue acute pain services during Covid-19}

The following are some of the challenges to the provision of acute pain management services during this pandemic:

1) Risk of cross infection in the respective postoperative wards for follow up acute pain service is a major concern. This is leading to need based analgesic supplementation and irregular pain management.

2) Placement of epidural or perineural catheters have reduced for the same reason mentioned above leading to ineffective pain relief. More over there may be less availability of infusion pumps in the wards during this pandemic.

*Correspondence: Samarjit Dey

E mail: drsamar0002@gmail.com

https://orcid.org/0000-0001-8211-253X

Received: 05/07/2020

Accepted: 23/09/2020

DOI: http:/doi.org/10.4038/slja.v29i1.8632
3) Regular assessment of pain may be hampered again due to less contact time with the patients.

4) Less importance may be given for postoperative pain at this crisis time.

Solutions to the challenges for continuing acute pain services during Covid-19

Implementation of acute pain service policies either by national or international societies, or at institutional level is required. Various societies did release recommendations for chronic pain ${ }^{3}$, but till date there are no recommendations for acute pain service or postoperative pain management.

1) Adequate PPE (Personal Protective Equipment) supply for acute pain service team should be available. Protective gear for suspected cases and positive cases should be used while providing adequate postoperative pain relief.

2) Intraoperatively, use of single shot nerve blocks, epidural, fascial plane blocks with adjuvants for prolonging the duration of analgesia has to be encouraged and implemented. Elastomeric pumps with larger capacity for continuous blocks can be used for 24 to 48 hours allowing less contact with patients.

3) Use of mobile phones to communicate with the patients or attendants can be another way to remotely assess the pain. Where such facilities are not available, a transparent barrier may be used by the physicians and nurses for interacting with the patients.

4) Self-reporting assessment tools in local languages may be used, so that the patients can report pain according to these tools, making pain evaluation easy during this pandemic.

5) Above all, a multimodal approach for managing postoperative pain should be continued, and a clear post-operative directive for breakthrough pain should be included. 


\section{Concluding reflections}

At this crisis period as more anaesthesiologists are diverted to COVID areas, managing acute pain service is challenging, but definitely not impossible. We must continue to strive for better postoperative pain control even in this crisis with the available solutions and implement a universal policy for the same.

\section{References}

1. WHO Director-General's opening remarks at the media briefing on COVID-19 - 11 March2020. [Internet]. [Cited2020]. Available from: https://www.who.int/dg/speeches/detail/whodirector-general-s-opening-remarks-at-the-mediabriefing-on-covid-19---11-march-2020.
2. K. Søreide, J. Hallet, J. B. Matthews, A. A. Schnitzbauer, P. D. Line, P. B. S. Lai, J. Otero, D. Callegaro, S. G. Warner, N. N. Baxter, C. S. C. Teh, J. Ng Kamstra, J. G. Meara, L. Hagander, L. Lorenzon, Immediate and long-term impact of the COVID-19 pandemic on delivery of surgical services, BJS (British Journal

Surgery), 10.1002/bjs.11670, 0, 0, (2020). https://doi.org/10.1002/bjs.11670 PMID: 32350857

3. Harsha Shanthanna et al. Recommendations on Chronic Pain Practice during the COVID-1 Pandemic. [Internet]. 2020. [Cited 2020]. Available from: https://www.asra.com/page/2903/recommendatio ns-on-chronic-pain-practice-during-the-covid-19pandemic. 